\title{
LITERATURA SURDA: CRIAÇÃO E PRODUÇÃO DE IMAGENS E
} TEXTOS

\section{Fabiano Souto Rosa}

\section{RESUMO}

O objetivo deste texto é analisar o uso da literatura como a construção da consciência de mundo, relacionando a interpretação com a realidade. A proposta é investigar a importância do uso da imagem e da linguagem na literatura, analisando a expressão de uma literatura surda.

\section{PALAVRAS-CHAVE}

Surdo; Imagem; Literatura; Língua de sinais brasileira.

\section{DEAF LITERATURE: CREATION AND CONSTRUCTION OF IMAGES AND TEXTS}

\section{ABSTRACT}

This paper aims to analyze the use of literature as the construction of world awareness, by relating interpretation and reality. We propose investigating the importance of using image and language in literature, by analyzing the expression of deaf literature.

\section{KEYWORDS}

Deaf; Image; Literature; Brazilian sign language. 


\section{ARTIGO \\ Literatura, Letramento e Práticas Educacionais \\ Grupo de Estudos e Subjetividade}

Ao surdo falta explorar e registrar seu imaginário e fantasia, bem como informação sobre a cultura e sua língua de sinais. Os materiais literários existentes carecem de uma maior estrutura e apoio lingüístico considerando a particularidade do Surdo.

Como o surdo utiliza a visão para obter informações, a união da mídia e da literatura cria condições para que haja um fortalecimento da identidade, cultura e de conhecimento da surdez. Pesquisar como se desenvolvem estes aspectos conjuntamente fará com que a expressão da arte e da literatura surda seja registrada em livros e em materiais midiáticos, capazes de manifestar a diferença lingüística e cultural de surdos, através do caminho da autorepresentação.

O livro é importante para todos aprenderem e estudarem, pois tem papel importante no contato das crianças com os mesmos. As crianças surdas desenvolvem aprendizagens através da leitura e da experiência visual, porém sozinhas não têm poder de se formar como leitoras e de serem também leitores visuais - necessitam do livro, de textos e de imagens para que possam desenvolver sua capacidade visual e de leitura. As crianças precisam encontrar significados que ultrapasse o sentido da leitura escolar e, preferencialmente, devem trazer de casa uma relação afetiva com os livros, construída com a família através da LIBRAS (Língua Brasileira de Sinais). Nessa experiência com leitura, lembro que quando eu era pequeno, aos 13 anos, tive o primeiro contato com o livro "Família Rato", lido pela turma na escola regular. Essa experiência foi significativa e até hoje lembro da importância que é ter contato com os livros para desenvolver a criatividade, conhecer coisas, e ter contato com a leitura, tanto de imagens quanto de textos.

Na Universidade Luterana do Brasil (ULBRA), no ano de 2001, comecei um trabalho voluntário de pesquisa sobre a questão da leitura e escrita de surdos. No ano seguinte, com uma bolsa de pesquisa da própria Universidade, comecei a praticar mais a leitura e a escrita e assim descobri gosto pela leitura e compreendi sua importância. Percebi que o livro é importante para informação, para o aprendizado e que é possível adaptar as histórias clássicas contadas, geralmente para ouvintes, para os surdos. As histórias que lia nas aulas de Português Instrumental para Surdos e também nas atividades de pesquisa eram divertidas, traziam informações, cultura e a possibilidade de explorar histórias que poderiam ser adaptadas e/ou criadas pelos próprios surdos, na LIBRAS. Com a leitura dessas histórias, comecei a adaptar e criar tantas outras histórias endereçadas principalmente aos surdos. Além 


\section{ARTIGO \\ Literatura, Letramento e Práticas Educacionais \\ Grupo de Estudos e Subjetividade}

disso, ao me basear nas leituras que fazia, comecei a utilizar esse aprendizado para conhecer mais a história da cultura surda, da identidade e da vida em comunidade.

O projeto de pesquisa do Curso de Mestrado em Educação - Processos Inclusivos (2006) - que comecei a desenvolver tem como tema a investigação da importância da literatura para as crianças e adultos surdos no Brasil.

A relevância dessa proposta de pesquisa, como tema de mestrado, está relacionada com o desejo que há muito tempo tenho de fazer uma criação de livros, associado à mídia (CD/DVD), apresentando e registrando a narração de histórias para as crianças e adultos surdos. Observo que em todo o Brasil ainda estão faltando muitos materiais direcionados para os surdos e seus interesses, principalmente livros em LIBRAS para crianças e adultos surdos. No Brasil, há muitas novidades para as crianças ouvintes, por exemplo: programa de TV com desenhos para crianças e adultos, mas infelizmente não tem legendas e/ou LIBRAS para surdos.

O ensino da leitura e da escrita para os alunos surdos, nos últimos anos, tem se desenvolvido, porém ainda não é habitual a escola utilizar livros, jornais, revistas e gibis para as crianças acrescerem seu conhecimento lingüístico e com isso facilitar a aprendizagem da escrita do português. Em geral, a escola acusa que os alunos não sabem ler ou que não gostam de ler e por isso não incentiva, não proporciona um ambiente adequado e com materiais diversificados para que ele possa descobrir a leitura e para que possa desenvolver o gosto pela leitura. As atividades de ensino de língua são, em geral, repetitivas, cansativas e sem desafios para que ele possa interagir com materiais escritos. Por causa dessa lacuna os alunos surdos têm muitas dificuldades para aprender a escrita de português e também não expandem o conhecimento para a comunicação de LIBRAS. Esse cenário mostra-se ainda mais caótico no momento em que presenciamos professores que trabalham com surdos, mas que não se comunicam na LIBRAS. Assim, o aluno não consegue transpor os significados de uma língua para outra. As experiências como contador de histórias mostraram-me que as crianças são naturalmente interessadas no visual e na LIBRAS. Mostrar que é do livro que saem as histórias legais que os adultos lêem é uma boa forma de apresentar uma relação adequada e coerente com a leitura desde cedo. No momento em que começar o processo de alfabetização, a criança vai querer ler.

Diz-se que a educação é má porque os professores não cumprem com sua obrigação, porque perderam sua vocação, porque estão sendo mal pagos, porque as crianças estão destruídas ou doentes, com capacidades intelectuais diminuídas, com alterações emocionais, com propensão sabe-se lá quais vícios, porque os pais não se 


\section{ARTIGO \\ Literatura, Letramento e Práticas Educacionais \\ Grupo de Estudos e Subjetividade}

preocupam com seus filhos, porque os valores foram perdidos, porque não existem políticas educativas, porque as autoridades não assumem suas responsabilidades, porque antes essas coisas não aconteciam e assim sucessivamente. (SÁNCHEZ, 2002, p.15).

Sánchez (2002) salienta os problemas encontrados na educação de surdos e, além disso, a família não sabe o que fazer com seu/sua(s) filho/a(s) surdo/a(s). A maioria do/a(s) professor/a(s) não sabe o que fazer em termos metodológicos para ensinar os aluno/a(s) surdo/a(s). O/a(s) professor/a(s) não tem formação adequada para proporcionar o aprendizado, criando, por exemplo, materiais para o aprendizado da escrita e da leitura de surdos. Não há a produção própria de livros de surdos e os professores reproduzem as metodologias direcionadas aos ouvintes. Dizem as autoras Rangel e Stumpf (2004, p. 88)

O professor ouvinte faz tudo para o surdo, mas desvaloriza suas contribuições. Quando as explicações, feitas em uma língua incompreensível, não surtem efeito, o surdo é rotulado como preguiçoso, como alguém que não se esforça para aprender.

Os professores ouvintes sempre fazem tudo para os alunos, não proporcionam o desenvolvimento da autonomia, porque a maioria dos professores ouvintes não sabe muito bem LIBRAS (Língua Brasileira de Sinais). Esse grande fracasso no ensino da escrita e da leitura dos alunos surdos é porque a maioria dos alunos surdos não tem muito interesse e gosto para aprender leitura e escrita, por que a escola não ensina e, consequentemente, o aluno não aprende.

Por outro lado, a maioria dos pais não sabe como ensinar as crianças surdas, pois não sabem muito bem a LIBRAS, o que dificulta a comunicação e com isso a transmissão de informação. Além disso, não têm disponibilidade para trabalhar com seus filhos. Em geral, os pais sempre levam e buscam os filhos da escola, depois voltam para casa, deixam sozinhos os filhos durante as brincadeiras realizadas de casa. O ambiente familiar, geralmente, não proporciona o aprender e o desenvolvimento da leitura e da escrita. Mas isso não é só uma questão de tempo, pois também esse problema ocorre em famílias as quais os pais não trabalham. O aprendizado da escrita e da leitura surge, muitas vezes, de situações em que a hora do conto é realizada nos lares.

Assim, as maiorias das famílias e dos docentes não têm informações sobre a educação de surdos, sobre a LIBRAS, a cultura surda, a(s) identidade(s) surda(s). Há poucos materiais de leitura sobre os surdos. Falta muita coisa, faltam informações e criação própria de surdos sobre suas histórias, sobre suas vidas, sobre sua língua. Por exemplo, a história de um professor ouvinte que morava da França, cujo nome era L’Epeé e que foi primeiro professor 
de surdos da França a dar aula para surdos utilizando a língua de sinais francesa - a maioria das pessoas não sabe sobre essa história dos surdos.

Metodologicamente, começo a contar a história do projeto de criar os livros para surdos. Queria fazer pesquisa sobre pessoas que contam histórias diferentes sobre o mundo e a vida de surdos. No artigo que publicamos na Revista de Iniciação Científica da ULBRA (ROSA et.al., 2003), discutimos o processo de criação de livros de literatura infantil e registramos que muitos dos livros de literatura são escritos por ouvintes, mas não apresentam uma literatura surda. Por esse motivo, precisamos fazer pesquisa para criar novos livros para surdos, mostrando também a língua de sinais, a cultura, a identidade surda, as histórias que aconteceram na vida de pessoas surdas etc...

O grupo de pesquisa do qual participo já publicou quatro livros de literatura surda, fazendo uma adaptação dos clássicos da literatura infantil para os surdos. Esse grupo é coordenado pela professora orientadora Lodenir Karnopp e tem como desenhista Carolina Hessel. Os dois primeiros livros de histórias infantis para surdos tiveram como primeira publicação o livro Cinderela Surda (HESSEL; ROSA; KARNOPP, 2003) e o segundo, Rapunzel Surda (HESSEL; ROSA; KARNOPP; 2003). Cada um dos livros contém em sua estrutura três itens principais: desenho e duas escritas: LIBRAS e português. O desenho é importante para crianças terem o visual e maior facilidade em perceberem o conteúdo do livro. Além disso, têm alguns desenhos de sinais expressando e marcando a cultura surda. Possui a possibilidade de leitura, pois dentro tem a escrita de língua de sinais. Este é novo sistema de escrita de sinais. Para compreender a escrita da língua de sinais a pessoa deve conhecer a estrutura da escrita de Língua de Sinais. E, por último, a leitura do português, que também é importante para aprender a ler o mesmo. Esses três itens têm como objetivo ajudar e compreender a cultura surda. Temos ainda "Patinho Surdo" (ROSA; KARNOPP, 2005) que narra uma história muito diferente daquele clássico infantil "Patinho Feio", não sendo considerado uma adaptação, mas sendo uma criação nova de uma história de patos surdos. Outra história publicada foi a história de "Adão e Eva" (ROSA; KARNOPP, 2005), uma história recorrente entre os surdos e que trata da origem das línguas. Precisamos de materiais que discutam a cultura surda, identidade surda, a língua de sinais, o visual etc...

Consideramos também importante incluir, nos livros de literatura surda, a escrita de sinais, conhecida como Sign Writing. Rangel e Stumpf (2004, p. 91) afirmam que aqui no Brasil este ensino deve começar a fazer parte do currículo das escolas, então, daí surge a necessidade de disponibilizar os livros infantis e de adultos a fim de que haja (c) ETD - Educação Temática Digital, Campinas, v.7, n.2, p.58-64, jun. 2006 - ISSN: 1676-2592. 
desenvolvimento de SIGN WRITING - meio importante para divulgação para conhecimento da própria escrita de língua de sinais dos surdos do Brasil.

Além de material impresso, a mídia (CD/DVD) é muito importante para surdos, pois apresenta visual para todos do Brasil e é um meio mais fácil para entender o livro. A recente oficialização de Língua Brasileira de Sinais (LIBRAS) (Lei n 10.436, de 24 de abril de 2002) que dispõe sobre a LIBRAS e dá outras providências, incentiva o uso da língua pelos pais ouvintes com filhos surdos, ou vice-versa. Melhor explicando, o reconhecimento da LIBRAS como idioma talvez facilitará a vida dos surdos em recepção de informações e em participação cidadã. “Assim, o livro Rapunzel Surda foi reconstruído a partir de pesquisa que considera a experiência visual do surdo, incluindo desenhos que tentam reproduzir expressões faciais e corporais”. (ROSA et.al., 2004 p. 228)

Imaginamos que a mídia tem muito para ajudar, já que mostra as imagens que pessoas surdas fazem em língua de sinais, apresentando a cultura, a identidade, as expressões faciais e corporais... A mídia é importante também para crianças para aprender LIBRAS, depois pode ser associada com mais facilidade à leitura de livros, desencadeando também o aprendizado da escrita. A mídia (CD/DVD) pode ajudar também no aprendizado e as escolas podem trabalhar com a LIBRAS, tendo um conhecimento melhor da língua de sinais, da identidade e do visual. Em muitos países se usa vídeo de VHS, CD e DVD. Agora eu queria continuar a fazer um trabalho de pesquisa aqui Brasil, pois acredito que a mídia vai ajudar muito no ensino de LIBRAS e proporcionar informações relevantes sobre os surdos.

Unificando o livro, imagem, ou melhor, livro e mídia, vislumbro um futuro com mais dignidade, compreensão do mundo e com opinião mais contemporânea para as crianças/adultos surdos.

\section{REFERÊNCIAS:}

BISOL, C.. Tibi e Joca - Uma história de dois mundos. Porto Alegre: Mercado Aberto, 2001.

COSTA, M. (Org). Estudos culturais em educação. Porto Alegre: UFRGS, 2000.

HESSEL, C.; ROSA, F.; KARNOPP, L. Cinderela Surda. Canoas: ULBRA, 2003.

HESSEL, C.; ROSA, F.; KARNOPP, L. Rapunzel Surda, Canoas: ULBRA, 2003.

KARNOPP, L. B. Língua de sinais e língua portuguesa: em busca de um diálogo. In: LODI, A. et al. Letramento e Minorias. Porto Alegre: Mediação, 2002. 
QUADROS, R. M.; KARNOPP, L. B.. Língua de sinais brasileira: estudos lingüísticos. Porto Alegre: Artmed, 2004.

RANGEL, G. M. M.; STUMPF, M. A Pedagogia da diferença para surdo. In: LODI, A. HARRISON,

K. CAMPOS, S. (Orgs.). et al. Leitura e escrita: no contexto da diversidade. Porto Alegre: Mediação, 2004.

ROSA, F.; KARNOPP, L. Adão e Eva. Canoas: ULBRA, 2005.

ROSA, F.; KARNOPP, L. Patinho Surdo. Canoas: ULBRA, 2005.

SILVEIRA, R. H. Contando história sobre surdos(as) e surdez. In: COSTA, M. (Org). Estudos culturais em educação. Porto Alegre: UFRGS, 2000. 